\title{
Subjective well-being among women with disabilities
}

\author{
Fatwa Tentama, Nina Zulida Situmorang, Muthmainah \\ Faculty of Psychology, Universitas Ahmad Dahlan, Indonesia
}

\section{Article Info}

Article history:

Received Aug 12, 2020

Revised Dec 20, 2020

Accepted Jan 3, 2021

\section{Keywords:}

Life satisfaction

Negative affect

Positive affect

Subjective well-being

Women with disabilities

\begin{abstract}
Women with disabilities are individuals who have double vulnerabilities. These vulnerabilities are arguably resulting from their condition as disabled persons and their status as a woman. Both women with innate disabilities factors and accident factors have a similarly negative view of their condition. This study aimed to describe subjective well-being in women with disabilities. The research method used was qualitative phenomenology. The data was obtained through semi-structured interviews. This study included six women with disabilities (visually impaired), aged between 20 to 30 years who lived in Yogyakarta and status as a graduate student. The data from interviews were analyzed with thematic analysis. The results showed that subjective well-being in women with disabilities was influenced by cognitive component (life satisfaction), which was indicated by self-acceptance, positive social relations, and perceived gratitude. Besides, the affective component also played a role. This component included positive affect, which was indicated by a sense of attention that the participant received, a feeling of excitement, pleasure, and a feeling of pride. Negative affect was indicated by feelings of sadness because of past negative relationships and feelings of disappointment.
\end{abstract}

This is an open access article under the CC BY-SA license.

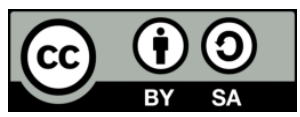

\section{Corresponding Author:}

Fatwa Tentama

Faculty of Psychology, Universitas Ahmad Dahlan

Kapas Street 9, Semaki, Umbulharjo, Yogyakarta, Indonesia

Email: fatwa.tentama@psy.uad.ac.id

\section{INTRODUCTION}

Every individual has different life experiences, and the level of happiness for each individual is certainly different. Happiness in positive psychology is known as subjective well-being. According to Diener and Oishi [1], subjective well-being is someone's cognitive and affective evaluation about their life. The cognitive evaluation is usually one's assessment of their life satisfaction. Meanwhile, emotional evaluation concerns with several situations in which a person experiences positive (pleasant feeling) and negative affect (an unpleasant feeling). Subjective well-being refers to an individual's assessment of whether his life is going well, and this evaluation is based on their point of view [2].

Individuals with high subjective well-being will get some positive impacts, one of which is better health and longevity [3]. Besides, people who have a high level of subjective well-being have a good quality of life, in which they can manage emotions, and deal with problems well. In comparison, people who have a low level of subjective well-being tend to have an unhappy life full of negative feelings and thoughts, which can further cause anxiety, anger, and even depression. Lyubomirsky [4] finds that happy people will be more successful throughout their life span than unhappy people.

Good subjective well-being is certainly expected by every individual, including people with disabilities who have certain problems such as physical abnormalities and physical disorders. It is not uncommon for people with disabilities to receive negative views from the surrounding community. These 
negative views or treatment are usually in the form of beliefs (stereotypes) and prejudices, which in the end becomes a barrier both from the surrounding people who see them and the disabled people themselves because they feel restricted [5].

Persons with disabilities experience limitations or disruptions to their social functions that affect the freedom of physical activity, trust, and self-esteem in dealing with others or with the environment. These conditions cause limited opportunities for socializing, going to school, and working, which can lead to discriminatory treatment from those who are normal [5].

Women are part of vulnerable groups [6]. Moreover, women with disabilities are also considered vulnerable. Therefore, it is important to consider risk factors that they might experience, such as sexual crimes and violence [7]. Knowing and understanding these risk factors further are extremely pivotal because these factors can be influential to their subjective well-being. Women with disabilities certainly live a different life from normal people. The difference is mainly found in their ability to deal with life challenges because it is highly affected by the severity of their physical disabilities. The heavier the level of disability that they have, the higher the burden that must be borne in their life. These burdens mainly relate to the negative treatment that they receive because of their condition. Besides, physical disability may also result in a limited capacity to undertake certain activities. Negative treatment and limited capacity are causing several major problems for them.

The problems and the risk factors which have been explained previously are also true for the participant in the present study. It can be seen from the results of interviews that have been conducted with E, the participant. E was born with a disability. E experiences difficulty in her daily life and education because of her physical limitations. For example, she has to be careful when walking into the classroom. She also feels awkward about the differences that she has. Consequently, even though she needs some sort of entertainment and wants to go out, she chooses to remain at home because of her condition. But E feels happy because she receives sufficient support from the disability service center (DSC). In this facility, she can find friends who have the same problem, and this platform may also create mutual care. Besides, E is also happy with the support of the family. In addition to $\mathrm{E}$, the researchers have also managed to interview $\mathrm{T}$. The results of interviews with $\mathrm{T}$ show that $\mathrm{T}$ has experienced disability since the age of 12 . It was found that $\mathrm{T}$ felt the physical condition she experienced was troublesome because she thought her condition would create a burden. T can only feel happy when interacting with people who accept her shortcomings, and those fellow disabled people because they share the same difficulties.

Based on the interviews, it is known that the subjects have faced difficulties in their daily lives. Besides, it is also known that they can feel happy when interacting with fellow disabled people. According to Diener, Suh, and Oishi [8], individuals are said to have high subjective well-being if they experience life satisfaction, joy, and rarely feel unpleasant emotions such as sadness or anger. Conversely, individuals are said to have low subjective well-being if they are dissatisfied with their lives, experiencing less joy and affection, and more often feeling negative emotions such as anger or anxiety.

Seeing the problems and the risk factors faced by women with disabilities has motivated the researchers to investigate the problems that they face because there is little, if any, research that specifically concentrates on subjective well-being of women with disabilities. Therefore, the researchers are interested in examining the "picture of subjective well being in women with disabilities". The purpose of this study is to obtain in-depth information about the life experiences of women with disabilities and how these experiences are associated with their subjective well-being.

\section{RESEARCH METHOD}

This study uses a qualitative phenomenological method to understand the meaning of the same experience from several individuals, which can then be explained universally [9]. This is done by collecting data from several informants to analyze these different experiences, which will be further processed, interpreted, and presented until the researchers get a result that can universally explain the problems being studied.

\subsection{Research subject}

This study employed a non-probability sampling technique to select the participants, and the participants are women with disabilities in Yogyakarta. Besides, this study uses a non-probability sampling technique. With this sampling technique, the researchers use a type of purposive sampling that is the technique of determining samples with specific considerations or characteristics that are in accordance with the desired objectives. The informants were selected by several inclusion criteria. The demographic data of the informants are shown in Table 1. The research subject criteria include: The subjects are female, subjects are persons with disabilities (visually impaired), subjects are in the age range of the early adult period (20 to 30 years) and status as a graduate student. 


\begin{tabular}{ccccccc}
\multicolumn{7}{c}{ Table 1. Characteristic of informant } \\
\hline & Informant 1 & Informant 2 & Informant 3 & Informant 4 & Informant 5 & Informant 6 \\
\hline Name (Initial) & $\mathrm{M}$ & $\mathrm{P}$ & $\mathrm{S}$ & $\mathrm{SF}$ & $\mathrm{TF}$ & $\mathrm{AR}$ \\
Age & 23 & 22 & 25 & 25 & 22 & 25 \\
Education & bachelor & bachelor & bachelor & bachelor & bachelor & bachelor \\
Gender & female & female & female & female & female & female \\
\hline
\end{tabular}

This study involved only six participants because number of qualitative research samples are not concerned about the number of the sample. Qualitative research is directed not at a large number of samples and not directed at representation but at the fit of the research context. The number of samples is very dependent on what is considered useful and can be done with the time and resources available.

\subsection{Data collection method}

The data collection method used in this study was a semi-structured interview (in-depth interview) designed with open-ended questions to obtain the informants' views and opinions. This was also supported by participant observation, which was carried out by researchers when conducting interviews. This was also an attempt to build rapport with the informants. Observations were done by using the anecdotal record method, which records the unique and important behavior of the subjects.

\subsection{Credibility}

The credibility of the data was ensured by member checking and triangulation of data. Member checking was followed, and the researchers submit the results of the final report to the informant to check the accuracy of the information captured. Data triangulation was operationalized by examining evidence from different informants to obtain the same information so that coherent data was obtained.

\subsection{Data analysis}

Qualitative data analysis begins by examining all available data from various sources, namely from interviews and observations that have been collected. The researchers then employed a thematic analysis to analyze the data. The steps undertaken in data analysis are as follows: (i) organizing data, (ii) making verbatims from recordings, (iii) reading and memoing, (iv) coding for emerging themes, (v) finding subthemes, (vi) categorizing, and (vii) interpretation.

\section{RESULTS AND DISCUSSION}

Based on the interviews with six informants, the researchers obtain information that captures how women with disabilities fight to achieve life satisfaction and how they deal with positive and negative affects:

\subsection{Observation result}

\subsubsection{Informant $1(M)$}

During the interview, the informant looked relaxed and confident to tell her experience. Occasionally, she smiled when she answered the questions. She also occasionally bowed when telling her experience, indicating unpleasant experience. The informant also did not hesitate to tell her experience.

\subsubsection{Informant $2(\mathbf{P})$}

The informant greeted the researchers kindly and reached out to shake hands. She also looked relaxed and did not hesitate to tell the story. Occasionally, the informant smiled when she answered the questions. She also did not hesitate to ask if there were questions that she didn't understand.

\subsubsection{Informant 3 (S)}

The informant looked friendly and smiled kindly after being invited into the interview rooms. Sometimes the informant also smiled and laughed during the interview. Occasionally, the informant also bent her head or looked away when she answered a question.

\subsubsection{Informant 4 (SF)}

Informant SF tended not to say much, but she answered the question calmly and occasionally smiled while telling the story. She also turned to ask the researchers when there were questions that she did not understand. She also occasionally lowered his voice when talking about his brother, who lived in the same household as her. 


\subsubsection{Informant 5 (TF)}

The informant looked cheerful when interviewed. Occasionally, she smiled and laughed when answering questions. The informant also looked relaxed when answering questions. And once in a while, the informant lowered her head and several times also moved her chair closer and spoke softly or whispered.

\subsubsection{Informant $6(A R)$}

When interviewed, informants sometimes answer questions with a relatively long answer. In some questions, informants tended to be silent. She also asked to repeat questions raised by researchers, for example, questions about her family.

\subsection{Interviews result}

\subsubsection{Self-acceptance}

Participants in this study describe that they have meaningful lives. They also accept their conditions well. It indicates that the participants have good life satisfaction, which can be seen from how they accept their current condition. They are more focused on the strengths that they have. It can be seen from the following quotation:

“...I am fine, I have accepted myself... .” (Informant 1, M)

"...I have accepted my condition, and I know that I am blind. I don't want to be bothered with that, and I want to focus on developing my strength." (Informant 1, M)

"I have adapted with my condition well, and I have accepted it." (Informant 2, P)

"I don't want to be bothered with my shortcomings, there's no point in thinking about it. I have fully accepted my condition. Now, I want to focus on the potentials that I have and to be admitted into a the university is also my strength." (Informant 2, P)

"I am happier now, accepting my current condition." (Informant $3, \mathrm{~S}$ )

"I don't think about my condition anymore, and I think God has been fair to me. Despite my disabilities, God also gives me some advantages. I have fully accepted my condition now." (Informant 3, S)

"I don't have problems with my condition, and I don't expect to achieve something. I am admitted into a university with a full scholarship (Bidikmisi). And I want to focus on developing my potential so that I can improve." (Informant 5, TF)

An individual who can accept themselves positively will feel satisfied with their life [10]. Selfacceptance is very important for every individual's mental health, and with self-acceptance, individuals can evaluate themselves well. A positive perspective encourages them to evaluate their shortcomings or mistakes, and this will help them to identify their unlimited potential that they can develop for their life [11]. Selfacceptance is an affirmation of self in which individual with self-acceptance will think that he/she is free from weaknesses or shortcomings [12]. Self-acceptance can be achieved by stop criticizing the shortcomings that exist in themselves and by feeling satisfied with their life. Thus, self-acceptance is a way to regulate one's emotions and behavior [13].

According to Oei, et al., [14], self-acceptance may influence someone's subjective well-being. Women with disabilities in this research have shown a kind of life satisfaction, which is evident from how they accept their conditions. They are more focused on their strengths and far more accepting of the current situation. Self-acceptance is the process of accepting all parts of oneself, be it good and bad, which is based on the assumption that nothing is perfect. But they at the same are also aware that they can try to improve themselves [15]. Brill [16] suggests that self-acceptance is related to self-esteem and self-confidence, but it is more important for mental health.

The informant has been able to adapt to their current condition and feel normal and can accept the shortcomings. Thinking about deficiencies is a waste of time and is pointless for informants. The most important thing for them is to focus on the advantages they possessed, such as being able to go to college with the scholarship path. The informants also say that every time there are shortcomings, there are advantages as well. The informants have drawbacks, but they also have benefits such as being able to continue school to college, which makes them aware that not everyone can get the privilege they have now.

\subsubsection{Positive social relationship}

One of cognitive evaluation in subjective well-being is life satisfaction, which includes relationships with oneself, family, and peer groups. Positive social relationships describe the informant relationship with the people around them. The results of this study suggest that participants have a good relationship with those closest to them, and this increases their life satisfaction. Their life satisfaction is also shown by good 
relationships with fellow disabled friends and good relationships with friends who are in normal conditions, including their neighbors. This is demonstrated by the chance that they get to involve in the same group and not being differentiated against. The following interview excerpts provide further information:

"My friends in DSC are all supportive. They are all kind and helping each other" My friends in my college the department is also very kind." (Informant $1, \mathrm{M}$ )

"Yes, I feel close to my older sibling. Every time I have a problem, I always talk to her, and she always helps me with my study." (Informant 1, M)

"She is indeed really kind; I will always be open to her and talk to her about my problem. She is the best." (Informant 1, M)

"Yes, all friends in DSC are very kind." (Informant 2, $\mathrm{P}$ )

"I am glad to have such a good friend in DSC." (Informant 2, P)

"I a good relationship with family too." (Informant 2, P)

"I often gather with my family at home, and I also often visit them. They are all very kind. No problems at all.” (Informant 2, P)

"Yes, very often, we are so close; we talk about anything." (Informant 2, P)

"I have good relations with friends, and there's no problem socializing at all." (Informant 2, P)

"I feel happier now because I have many good friends, and families, the relationship is getting better." (Informant 2, P)

"I have good relations with friends, and they often help me when I have a problem." (Informant 3, $\mathrm{S})$

"All good, no problem, I have a good relationship with friends, families, and neighbors." (Informant $3, \mathrm{~S})$

"I don't feel discriminated by neighbors, They know me since I was born and we always spend time Together." (Informant 4, SF)

"Yes, good, I am also close to my families." (Informant 5, TF)

"We often gather and talk. They are very kind. They always help me when I need help." (Informant $5, \mathrm{TF})$

"My family often takes me to meet with my friends." (Informant 5, TF)

"No conflict at all, I am really glad to have DSC, they are kind, and I can have so many friends. " (Informant $6, \mathrm{AR})$

Life satisfaction is also felt the participants because it is consciously evaluated by them when they have a good social relationship. This can further increase life satisfaction [17]. Individuals who have such a closeness with others and have supportive friends and family tend to be satisfied with their entire lives [18]. The informant's life satisfaction is shown by good relations with their friends, especially with fellow friends with disabilities. These friends are those in the same community (DSC). For the participants, they are very kind people. The goodness can be seen from the existence of mutual assistance that they have, such as reading books and helping others with their assignments. The presence of DSC on the campus makes informants feel that they have many friends. In addition, the informant often shares stories with their friends, and this makes them feel close. This is supported by the results of previous studies. The study evaluates the intensity of the meeting and assesses the quality of friendship. The result suggests that a good friendship and relationship are associated with life satisfaction in individuals [19].

Some informants have families who always give them support in terms of education. The family encourages informants to continue learning, and one example of support came from one of the informant's brothers. Following the research results conducted by Sim and Bang [20], family support has a positive influence on individual life satisfaction. One of the informants in this study has a close relationship with her brother, which is shown by sharing stories. The informant is open with her brother and not hesitate to share her stories and activities on campus. Besides, positive social relationships are indicated by frequent gatherings with others. In this research, it can be seen from how the participants often visit their family's house. This becomes an opportunity for the family to assist when the participants feel distressed. For example, one of the participants was escorted to a difficult place for her to reach. Supported by research conducted by Nguyen, et al. [21], it is known that the close relationship with family can increase individual life satisfaction.

\subsubsection{Gratitude}

The life satisfaction experienced by the informants is also indicated by the presence of gratitude. The informants are thankful because they are able to continue their education at university and has many friends. The informants also are grateful for the existence of DSC on campus, which helped them a lot during 
college. Gratitude describes the response or assessment of individuals who are constructive and positive about their living conditions now and in the future so that there is hope [22]. It can be seen from the following interview excerpts:

"I am really grateful because I can pursue higher education and have many friends." (Informant 1, M)

"I feel the warmth in DSC, and I am really grateful for that because it helps me a lot with my study." (Informant 1, M)

"I don't have other words, I am just grateful for being able to get into a university." (Informant 2, P)

"I am grateful to have many good friends in DSC." (Informant 2, P)

"I am grateful to have many good friends in DSC. DSC is really helpful. "I am just grateful for being able to attend a college." (laugh) (Informant 3, S)

"I can only feel thankful because I can pursue higher education in a university." (Informant 6, AR)

The results of the interview above are in accordance with the results of research conducted by Sapmaz et al., [23]. It reveals the existence of the effect of gratitude towards subjective well being. Gratitude is positive emotions or responses to the life that someones experienced to increase their well-being. Gratitude is an emotional state and attitude towards life that becomes a source of human strength in improving personal well-being [24]. As an emotional construction, gratitude is characterized by the ability to change the emotional response to an event so that it becomes more meaningful [25]. As a cognitive construction, gratitude is shown by acknowledging the generosity, kindness, and blessings that have been received, which lead an individual to focus on positive things.

The interview results above are also supported by the statement of Emmons [26], who explains that gratitude is a pleasant feeling about the benefits received by someone. A person who has gratitude is those who confirm that something good has happened to them and realizes that something good is coming from someone else (the environment) and is beneficial to them [27]. Bono, Krakauer, and Froh [28] also explained that gratitude is a feeling experienced by people when they receive "gifts" or benefit from others. Gratitude is a feeling that occurs in exchange-based human relationships, where someone acknowledges that he/she has received valuable benefits from others [29].

\subsubsection{Positive affect}

Positive affect or pleasant emotions are part of the subjective wellbeing that arises in individuals because life goes according to what they have expected [1]. According to Diener [18], individuals can be said to have high subjective well-being if they often feel positive emotions such as being attentive, interested, alerted, excited, enthusiastic, inspired, proud, determined, strong, and active. The positive affects can be seen from the following interview excerpts:

"Thank god, my families always have a positive view and give caring and support to me." (Informant 2, P)

"My siblings and families are so caring. They give attention to me. My families are more caring to me." (Informant 2, P)

"My parents accept me as who I am, thank god". They really care and love me." (Informant 3, S)

"Yes, they often call me asking how I am, and my study. they often ask about how I go through every day's

Activities." (Informant 3, S)

"My parents are really caring even though I am away." (Informant 4, SF)

"...they often call me, asking how I am and how my study is." (Informant 4, SF)

"Of course, I am happy to get such attention from my mother." (Informant 4, SF)

"My families are all good, they don't restrict me to do things, they are also caring, too. " (Informant 5, TF)

"When I get back home, my families often send some foods. They also ask about my condition; they always help me. So caring!.” (Informant 6, AR)

Positive affect on the informant can be seen when the informant felt cared for by others. The informants felt that they were cared for by their family and siblings. The family also has a concern about the informants, which could be seen from when parents often called and asked about their condition and their study. Families often asked about daily activities that they did on or off-campus. Likewise, the informants' brothers were also caring, and they often brought some foods when the informants were going back home. 
The family was always caring for the informant's condition, and they also often assisted when the informants had difficulties. The attention to the informant was also shown when the informant wore a hijab that did not suit her clothes, so the family gave advice to the informant. The attention given to the informants raises positive affect, and this is supported by the research of Tough, Siegrist, and Fekete [30], which reveals that support or attention obtained from dominant family and friends influences the well-being of persons with disabilities, specifically influencing their positive emotions to fight stressors.

Another positive affect that the informant has is enthusiasm. Individuals are said to have high subjective well-being if they often feel positive emotions such as enthusiasm [18]. Informants were eager to continue learning and trying their best to be able to finish college immediately. Some informants want to be teachers and make their parents happy. The informant's spirit was shown by their diligence to attend lectures and hard work to study so as not to fail a certain course. The informant made the best use of time and was not lazy. Utilizing time with a lot of reading was an attempt of the informant as an expression of the enthusiasm to continue learning. This can be seen from the following interview excerpts:

"I have to study and be diligent because I don't want to fail in a course. The most important thing for me is to do the best to get things better." (Informant 1, M)

"Yes, I don't want to waste time. That is why I am eager to learn and do not be lazy." (Informant 1, M)

"I have to be eager to learn, not being lazy because I want to be a teacher in a special education school." (Informant 3, S)

"I need to be more ager, reading books, doing the assignment on time, and being diligent." (Informant 3, S)

"I need to keep studying, be eager, always. I want to be a teacher in a special education school." (Informant $4, \mathrm{SF})$

"I have to finish college and become a teacher in a special school." (Informant 4, SF)

"be diligent always, so that I won't be left behind. I want to do my best and to keep studying." (Informant $5, \mathrm{TF})$

"keep the eagerness to learn to achieve my goal." (Informant 5, TF)

Another positive affect the informant has is a pleasure. Informants are happy that they are given a chance to speak by being involved in various activities. Participating in many activities makes informants happy. For example, one of the informants was asked to be one of the speakers at a seminar. The informants are always passionate to share their experiences to motivate others. Being a resource of motivation for others makes them worthy of being accepted with all of their shortcomings. In addition, some informants were also happy to show their talent such as singing. They are also involved in many events both in their village and in another place. Diener and Oishi [1] state that positive affection is characterized by emotional transition and pleasant mood. Positive affection also contains pleasure. The following interview excerpts:

"I am so happy to be involved in some events even though not the big one. It makes me happy because I feel recognized." (Informant $1, \mathrm{M}$ )

When there are some events in my village, I am always involved, and I am really happy." (Informant $2, \mathrm{P})$

"For example, when there is a celebration, they asked me to participate. I am glad because I can be useful for others." (Informant 2, P)

"I participated in one event where I am the only disabled person. It's just amazing for me and I am really happy." (Informant $3, \mathrm{~S}$ )

"I'd be very happy to participate in such an event." (Informant 5, TF)

"I am happy to share my experiences with others." (Informant 5, TF)

Based on interviews, the informants also felt another positive affect, namely pride. According to Seligman et al., [31], there are several positive emotions about the past, including satisfaction, relief, success, pride, and peace. The pride shows this positive emotion about the history that was felt by informants. Informants feel proud of themselves because they can study up to now, and it is a matter of pride because other people may not get the same opportunity as the informant. The informant did not expect that they would be given such an opportunity to learn. Opportunities to study in college can also be used as a reinforcement for them to think that they can be like a normal person who continues to learn. The following interview excerpts: 
“Honestly,... I'm happy I can still go to college. If you say you are proud, you are proud ... because many of my friends who were unable to continue their studies and it is a pride for me to be able to continue my study. Not all people with disabilities can go to college like I do, especially women." (Informant 1, M)

"Yes, of course, I am proud,... but I don't want to be arrogant. It means that I am proud to be able to study until now, you never thought. I am a disabled person, but I was still allowed to learn." (Informant 2, P)

"Being able to study until now is pride, for me. Not all people can go to college, even normal people. (laugh)." (Informant 3, S)

"Wow, I'm happy... moreover, I am the only disabled person who received a scholarship. So, yes, I am proud. ... proud of myself. I am proud to be able to go to college and get a scholarship too." (Informant 5, TF)

\subsubsection{Negative affect}

In addition to the positive affect, the informant also has a negative affect. Negative affect includes unpleasant moods, which reflect negative responses experienced by individuals about their lives [1]. Negative feelings can be seen from specific emotions such as sadness, distress, disappointment, guilt, scare, hostility, shame, nervousness, and worry.

The informants' negative affect is the feeling of sadness due to a lack of harmonious past relationships with family, friends, siblings, and neighbors. The informant once felt sad when he was ostracized and underestimated by their neighbors. The neighbor's negative attitude, for instance, was in the form of prejudice and negative thinking about informants' inability to attend school. Besides, some of the informants had been underestimated by their siblings. The informant was underestimated when they were about to enter college. Their siblings consider the informants as unable, and letting them go to university would be just wasting money. This condition makes them sad. In addition to neighbors and relatives, the informant also felt sad about the treatment from their friends in the past. Informants have been slandered and despised by their friends. These negative pas experiences can be seen in the following interview excerpts:

"Yes, my neighbors just don't care, and it's like being left out, ostracized. Maybe they think I cannot do anything and it is really sad." (Informant $1, \mathrm{M}$ )

"People often look down to me, they said " why you want to go to college? What will you be?" I'm so sad to hear that, I'm crying." (Informant 1, M)

"Yes, they underestimate. Sometimes they don't hear me when I talk... I feel resentful and sad too." (Informant 2, P)

"... it's really sad. I was always ostracized, bullied, mocked when I was in high school." (Informant $2, \mathrm{P})$

"When I was in elementary school, I was mocked, even by my teacher too. I was prohibited from joining a lesson, she said I couldn't do it ... just sad .. why am I different from my friends. Even though I know, I can too." (Informant 3, S)

"Yes, my friends here often gossiped about me. It's sad sometimes." (Informant 4, SF)

Another negative affect felt by the informant is a feeling of disappointment. Feelings of disappointment that were experienced by the informants are associated with the issue of schooling age. Some of the informants had attended school for a longer period because of their disabilities so that their age was slightly above the average of their friends'. It becomes a source of negative feelings for the informants. In addition, the informant also felt disappointed because this problem has further prevented the informants from attending university earlier. It makes them think that if they are not disabled, they may have a bigger chance to finish their education earlier and faster. The following interview excerpts tell the story about their schooling problem:

"I am angry with myself often, yes, because I am blind. Sometimes I also feel sorry and disappointed why I have to be like this." (Informant 4, SF)

"Yes, bored. I am already in my 25s, but I am only in the 6th semester. I want to finish college, I just want to finish it soon ... ." (Informant 4, SF)

"Yes, that was disappointing and boring. It doesn't suit my age."

(Informant 4, SF)

"Yes, disappointed,...at my age, I haven't graduated yet. I'm disappointed that my study has to be delayed." (Informant 6, AR)

"I was disappointed ... so far I am still curious about how the world is." (Informant 6, AR) 


\section{CONCLUSION}

Subjective well-being in women with disabilities is illustrated by the presence of satisfaction in several domains, namely self-acceptance, positive social relations, and gratitude. The informants were satisfied with their life, and they described their life as meaningful because they wholeheartedly accept their current condition. This positive feeling also leads them to be more focused on what they can do with the potentials that they have. The informants have a good relationship with the people around them. The life satisfaction of the informants was also seen from good relations that they build with fellow disabled friends. In addition, the informants' life satisfaction was also indicated by gratitude. The informants were grateful that they were able to continue their education until university level. They were also grateful for the help and support that DSC has provided.

The positive affect of informants can be seen from the sense of attention that is obtained, feelings of enthusiasm, pleasure, and a feeling of pride. They also feel the attention and care from their family and sibling. However, they used to have negative past experiences with their family and neighbours, which made their relationship less harmonious. The informants still feel sad because of their negative past experiences. Besides that, they also feel disappointed with their education experience. Their status as a disabled person has prevented them from finishing school on time. Some informants even had not gone to school for several years because of their disabilities, so that they felt negative emotions in themselves.

\section{ACKNOWLEDGEMENTS}

The authors wish to thank the Ministry of Research and Technology/National Research and Innovation Agency, Republic of Indonesia (RISTEK-BRIN), for providing support and funding for the completion of this research.

\section{REFERENCES}

[1] Diener, E., Lucas, R. E., Oishi, S., "Subjective well-being: The science of happiness and life satisfaction," Handbook of Positive Psychology, pp. 63-73, 2002.

[2] Diener, E., Lucas, R. E., Oishi, S., "Advances and open questions in the science of subjective well-being," Collabra Psychology, vol. 4, no. 1, pp. 1-78, 2018, doi: https://doi.org/10.1525/collabra.115.

[3] Diener, E., Chan., M. Y., "Happy people live longer: Subjective well-being contributes to health and longevity," Journal of Applied Psychology: Health and Well Being, vol. 3, no. 1, pp. 1-43, 2011, doi: https://doi.org/10.1111/j.1758-0854.2010.01045.x.

[4] Lyubomirsky, S., "The myths of happiness: What shpuld make you happy, but doesn't, what shouldn't make you happy, but does," New York: Penguin Press, 2013.

[5] Lahey, B., "Psychology an introduction," Chicago: McGraw Hill, 2004.

[6] Genugten, W. V., "Human rights reference," Netherlands: The Hague, 2011.

[7] Dixon, J., Robb, M., "Working with women with a learning disability experiencing domestic abuse: How social workers can negotiate competing definitions of risk," British Journal of Social Work, vol. 46, no. 3, pp. 773-788, 2015, doi: https://doi.org/10.1093/bjsw/bcu149.

[8] Diener, E., Suh, E., Oishi, S., "Recent findings on subjective well-being," Indian Journal of Clinical Psychology, vol. 24, no. 1, pp. 25-41, 1997.

[9] Creswell, J. W., "Research design: Qualitative, quantitative, and mixed methods approaches," Thousand Oaks, California: SAGE Publications, 2014.

[10] Hurlock. E. B., "Developmental psychology," New York: McGraw Hill Education, 2001.

[11] Carson, S. H., Langer, E. J., "Mindfulness and self-acceptance," Journal of Rational-Emotive and CognitiveBehavior Therapy, vol. 24, no. 1, pp. 29-43, 2006, doi: https://doi.org/10.1007/s10942-006-0022-5.

[12] Bernard, M. E., "The strength of self-acceptance," London: Springer, 2013.

[13] George, B., "Discover your true north, expanded and updated edition," New Jersey: John Wiley \& Sons, Inc., 2015.

[14] Xu, W., Oei, T. P., Liu, X., Wang, X., Ding, C., "The moderating and mediating roles of self-acceptance and tolerance to others in the relationship between mindfulness and subjective well-being," Journal of Health Psychology, vol. 21, no. 7, pp. 1446-1456, 2014, doi: https://doi.org/10.1177/1359105314555170.

[15] Williamson, A., "Self-esteem and self-confidence," The handbook of contemporary clinical hypnosis: Theory and practice first edition, New Jersey: John Wiley \& Sons, Ltd., pp. 157-167, 2012.

[16] Brill, R. R., "Emotional honesty \& self-acceptance: Education strategies for preventing violence," USA: Xlibris Corporation, 2000.

[17] Diener, E., Lucas, R. E., Oishi, S., "Subjective well-being: The science of happiness and life satisfaction," Handbook of Positive Psychology, New York City: Oxford University Press, 2005.

[18] Diener, E., "The science of well-being: The collected works of Ed Diener," New York City: Springer Science, 2009.

[19] Amati, V., Meggiolaro, S., Rivellini, G., Zaccarin, S., "Social relations and life satisfaction: The role of friends," Genus, vol. 74, no. 7, pp. 1-18, 2018, doi: https://doi.org/10.1186/s41118-018-0032-z.

[20] Sim, S., Bang, M., "A study on the depression, family support and life satisfaction in the elderly," The Korean Journal of Rehabilitation Nursing, vol. 20, no. 2, pp. 122-128, 2017, doi: http://doi.org/10.7587/kjrehn.2017.122. 
[21] Nguyen, A. W., Chatters, L. M., Taylor, R. J., Mouzon, D. M., "Social support from family and friends and subjective well-being of older African Americans," Journal of Happiness Studies, vol. 17, no. 3, pp. 959-979, 2016, doi: https://doi.org/10.1007/s10902-015-9626-8.

[22] Froh, J. J., Yurkewicz, C., Kashdan, T. B., "Gratitude and subjective well-being in early adolescence: Examining gender differences," Journal of Adolescence, vol. 32, no. 3, pp. 633-650, 2009, doi: https://doi.org/10.1016/j.adolescence.2008.06.006.

[23] Sapmaz, F., Yıldırım, M., Topçuoğlu, P., Nalbant, D., Sızır, U., "Gratitude, forgiveness and humility as predictors of subjective well-being among university students," International Online Journal of Educational Sciences, vol. 8, no. 1, pp. 38-47, 2016, doi: http://dx.doi.org/10.15345/iojes.2016.01.004.

[24] Emmons, R. A., Crumpler, C. A., "Gratitude as a human strength: Appraising the evidence," Journal of Social and Clinical Psychology, vol. 19, no. 1, pp. 56-69, 2000, doi: https://doi.org/10.1521/jscp.2000.19.1.56.

[25] Dewanto, W., Retnowati, S., "Gratitude and welfare interventions for persons with physical disabilities (in Indonesia)," Gadjah Mada Journal of Professional Psychology, vol. 1, no. 1, pp. 33-47, 2015, doi: https://doi.org/10.22146/gamajpp.7359.

[26] Emmons, R. A., "The psychology of gratitude," New York: Oxford University Press, 2004.

[27] Watkins, P. C., Scheibe, D., "Gratitude," In Maddux, J. E., "Subjective well-being and life satisfaction," New York: Routledge, pp. 210-229., 2018.

[28] Bono, G., Krakauer, M., Froh, J. J., "The power and practice of gratitude," Positive psychology in practice: Promoting human flourishing in work, education, and everyday life, New Jersey: John Wiley \& Sons, Inc., pp. 559-575, 2015.

[29] Lomas, T., Froh, J. J., Emmons, R. A., Mishra, A., Bono, G., "Gratitude interventions: A review and future agenda," The wiley blackwell handbook of positive psychological interventions first edition, New Jersey: John Wiley \& Sons, Inc., pp. 3-19, 2015.

[30] Tough, H., Siegrist, J., Fekete, C., "Social relationships, mental health and wellbeing in physical disability: A systematic review," BMC Public Health, vol. 17, no. 1, pp. 1-18, 2017, doi: https://doi.org/10.1186/s12889-0174308-6.

[31] Seligman, M. E., Steen, T. A., Park, N., Peterson, C., "Positive psychology progress: Empirical validation of interventions," American Psychologist, vol. 60, no. 5, pp. 410-421, 2005, doi: https://doi.org/10.1037/0003066X.60.5.410. 